\title{
OS PROCESSOS DE CIRCULAÇÃO DO CASO PABLO KATCHADJIAN
}

\author{
Nair Renata Amâncio \\ Mestranda em Estudos de Literatura pela \\ Universidade Federal de São Carlos (UFSCAR). Bolsista CAPES. \\ nairrenataamancio@gmail.com
}

\section{RESUMO}

Apresentaremos o conceito de Objetos Derivados e a sua pertinência para pensar os processos de circulação do livro EI Aleph Engordado (2009). O conceito é fruto da pesquisa $A$ rasura da autoria na literatura contemporânea: O caso Pablo Katchadjian (Processo FAPESP: n-2017/25218-0) na qual construímos uma proposta de leitura para os objetos (\#Yoborges, Reality Avoider e Apoyo a Pablo Katchadjian) que surgiram por consequência da publicação do livro El Alpeh Engordado (2009) que fez uso do conto El Aleph (1949) do celebre Jorge Luís Borges (1986). Discutiremos o Caso Pablo Katchadjian dando ênfase em seus objetos derivados e colocando em questão novas possibilidades de compreensão para a autoria no tempo presente.

Palavras-chave: Objetos derivados; El Aleph Engordado; Pablo Katchadjian; Autoria.

\section{RESUMEN}

Presentaremos el concepto de Objetos derivados y su conveniencia para pensar los procesos de circulación del libro El Aleph Engordado (2009). El concepto es resultado de la investigación $A$ rasura $d a$ autoria na literatura contemporânea: $O$ caso Pablo Katchadjian (Processo FAPESP: $\mathrm{n}$-2017/25218-0) en la cual desarrollamos una propuesta de lectura para los objetos digitales (\#Yoborges, Reality Avoider y Apoyo a Pablo Katchadjian) que han surgido en consecuencia de la publicación del libro El Aleph Engordado (2009) que hace uso del cuento El Aleph (1949) de Jorge Luís Borges (1986). Discutimos El Caso Pablo Katchadjian poniendo énfasis en los objetos derivados y cuestionando nuevas posibilidades de comprensión para la categoría autoral en el tiempo presente.

Palabras clave: Objetos derivados, EI Aleph Engordado, Pablo Katchadjian, Autoría 


\section{O Caso: Apresentação}

No ano de 2009, o escritor argentino Pablo Katchadjian publicou o livro El Aleph Engordado, fruto da apropriação do conto “El Aleph" (1949) de autoria do consagrado escritor argentino Jorge Luis Borges (1986). O procedimento de apropriação se converteu em um Caso. María Kodama, viúva de Borges, acusou o autor de El Aleph Engordado (2009) de apropriação indevida da propriedade intelectual do marido, o que deu início a uma série de acontecimentos que constituem o que entendemos como o Caso Pablo Katchadjian

A problemática do Caso se dá entorno da publicação de um autor contemporâneo que toma como objeto (para a realização de um procedimento artístico) o conto "El Aleph" (1949) do consagrado Jorge Luis Borges. O trabalho de apropriação foi entendido como um plágio e Katchadjian foi processado por Maria Kodama ${ }^{1}$. Desse processo judicial surge uma série de discussões que reverberam na criação de objetos culturais pertencentes ao contexto digital. É importante ressaltar que os 300 exemplares produzidos de modo independente pelo próprio Pablo Katchadjian, através da IAP (Imprenta argentina de poesia), foram distribuídos gratuitamente, argumento que não bastou para que María Kodama retirasse o processo.

"El Aleph" (1949) possui aproximadamente 4.000 palavras. O texto "engordado", 9.600 palavras. Katchadjian retoma El Aleph de Borges ao se apropriar do conto integralmente, apenas acrescentando palavras a este como podemos ver nos excertos abaixo:

La candente y húmeda mañana de febrero en que Beatriz Viterbo finalmente murió, después de una imperiosa y extensa agonía que no se rebajó ni un solo instante ni al sentimentalismo ni al miedo ni tampoco al abandono y la indiferencia, noté que las horribles carteleras de fierro y plástico de la Plaza Constitución, junto a la boca del subterráneo, habían renovado no se qué aviso de cigarrillos rubios mentolados; o sí, sé o supe cuáles, pero recuerdo haberme 
esforzado por despreciar el sonido irritante de la marca; el hecho me dolió, pues comprendí que el incesante y vasto universo ya se apartaba de ella, Beatriz, y que ese cambio era el primero de una serie infinita de cambios que acabarían por destruirme también a mí. (KATCHADJIAN, 2009, p. 1, grifo nosso)

La candente mañana de febrero en que Beatriz Viterbo murió, después de una imperiosa agonía que no se rebajó un solo instante ni al sentimentalismo ni al miedo, noté que las carteleras de fierro de la Plaza Constitución habían renovado no sé qué aviso de cigarrillos rubios; el hecho me dolió, pues comprendí que el incesante y vasto universo ya se apartaba de ella y que ese cambio era el primero de una serie infinita. (BORGES, 1949, p. 87)

A única parte do conto que Katchadjian não "engordou" foi a pós-data deixada por Borges - 1 de março de 1943 - mas, em contrapartida, Katchadjian também deixou no livro sua própria pós-data, na qual explica em que consistiu o procedimento de "engordamento".

A atitude de explicar o próprio trabalho é característica de um escritor que está alinhado aos novos paradigmas de criação. Como aponta Cesar Aira (2009), Kachadjian amplia o conto "por dentro", realizando um tipo de apropriação em que a memória de Borges se mantém e manter a memória desse autor, nesse Caso, é significativo, por todas as questões que a autoria de Borges evoca, principalmente por seu renome que está estritamente associado a sua canonização.

El Aleph Engordado. Se trata del cuento de Borges ampliado, ampliado "por dentro", agregando palabras, frases, episodios, "catalizando" mediante aposiciones sin cambiar el argumento ni agregar personajes, de modo de hacer del cuento de diez páginas una novela, breve pero novela, o más bien, para no entrar en la discusión de los géneros, "un libro"2. (AIRA, 2009, p. 9)

A proposta de Katchadjian, de produzir por meio de um texto pré-existente e ainda categorizá-lo, dialoga com o conceito de pós-produção, que "corresponde tanto a uma multiplicação da oferta cultural quanto - de forma mais indireta - à anexação ao mundo da arte de formas até então ignoradas ou desprezadas" (BOURRIAUD, 2009, p. 7- 
8). Artistas como Katchadjian não estão em busca de originalidade, pois suas produções não se dão por meio de matéria bruta, mas sim com base em obras pré-existentes, permitindo-nos pensar em reinterpretação do literário e até mesmo na ressignificação do conceito de originalidade.

Em muitos momentos, esses procedimentos de apropriação são encarados como uma performance autoral. Luciene Azevedo (2011), ao mencionar um caso específico ${ }^{3}$ de apropriação seguida de acusação de plágio, coloca em discussão a performance quando ocasionada pela recepção, como ocorre no Caso Pablo Katchhadjian. A própria acusação de plágio acaba orientando a performance do autor:

\footnotetext{
Nesse sentido, a própria recepção crítica da obra, uma vez apontado o plágio, pode representar o primeiro ato de uma performance dirigida pela própria audiência, pois a mobilização de críticos, professores e inúmeros outros leitores que intensificaram antes de qualquer manifestação do autor, seu desempenho no episódio, ditando-lhe uma atuação a partir do momento em que circunscreveram a discussão a questão do plágio, a tal ponto que as declarações posteriores do autor podem apenas obedecer as rubricas das declarações acaloradas disponíveis na Web. (AZEVEDO, 2011, p. 54)
}

Pode-se dizer que o primeiro ato que insere Katchadjian no meio literário, enquanto autor performático, é a acusação de plágio. Uma vez acusado, o autor rejeita a acusação e, a partir daí, passa a dar declarações que vão contra a de um plagiador, criando para si uma categoria própria, performática. Ironicamente, María Kodama, ao tentar deslegitimar Katchadjian, contribuiu para o seu reconhecimento, dando-lhe a chave para a criação da performance autoral.

Esse Caso coloca em jogo o conceito de autoria na cena contemporânea, ao mesmo tempo em que questiona a legitimidade do lugar canônico atribuído a certos autores, chamando a atenção para questões relativas ao surgimento dos direitos autorais e seu anacronismo com relação às práticas contemporâneas. 
A acusação de plágio contra Katchadjian se deu com base na lei 11.723 de 1933 da Argentina, lei que resguarda os direitos do autor e seus herdeiros legais. No caso de Borges, María Kodama é a única herdeira legal. A lei também mostra em seu Art. $9^{\circ}$ que: "Nadie tiene derecho a publicar, sin permiso de los autores o de sus derecho habientes, una producción científica, literaria, artística o musical que se haya anotado o copiado durante su lectura, ejecución o exposición públicas o privadas"4 (ARGENTINA, 1933). De acordo com esse artigo da lei, seria plágio se houvesse uma cópia total, e o trabalho de Katchadjian não é uma simples cópia do texto de Borges, mas sim um procedimento de apropriação cujos efeitos estéticos não condizem com o que consta numa lei de propriedade autoral definida com base em regimes jurídicos.

Nesse sentido, há um distanciamento entre as especificidades do meio literário e do meio jurídico. Estamos nos referindo a um tipo de procedimento que requer estudo e análise dos processos de produção, circulação e recepção do literário, o que parece apresentar uma incompatibilidade com a leitura técnica realizada no âmbito judicial.

\section{Os objetos Derivados do Caso}

O Caso Pablo Katchadjian envolve ainda o surgimento de três objetos propiciados por esse contexto de circulação e recepção: "Apoyo a Pablo Katchadjian", "\#YoBorges" e o jogo Reality Avoider. Toda a discussão entorno de "El Aleph Engordado" (2009) gera um atrito entre plagio e apropriação, entre original e cópia, provocando, ainda, uma discussão entre a legitimidade da figura autoral de Borges e a de Katchadjian. Para o desenvolvimento da pesquisa foi significativo pensar na noção de Caso, uma vez que é por meio das reverberações da publicação que surgem os dizeres que vão atribuir significado ao objeto literário na sua situação real de circulação. Assim, a noção de Caso 
nos permite pensar o literário por meio de uma perspectiva contingente, que valore os processos de circulação do texto. Nossa leitura está embasada nos pressupostos de Canclini:

A sociologia da produção artística (não das obras) surge do pressuposto antirromântico de que é possível entender mais a arte se - em vez de ver seus resultados como imprevisíveis - indagamos o que os criadores devem a seu entorno, como se formam e qualificam, como constroem as regras de avaliação de um quadro ou de um espetáculo junto com outros profissionais, tendo em conta os virtuais receptores e as instituições que medeiam entre uns e outros. (2016b, p. 143)

O procedimento de apropriação se dá por meio de uma leitura que converge em diversas categorias, sendo conceitos bases a reciclagem cultural (KLUSCINSKAS; MOSER, 2007) e a autoria na pós-produção (BOURRIAUD, 2009).

Essa discussão, alinhada ao conceito de reciclagem cultural, nos permite mobilizar categorias de análise que contemplem as especificidades requeridas pelo procedimento de apropriação, sendo elas: citação, remix, mashup, redymade, entre outras.

O princípio fundamental do conceito de reciclagem cultural é a realização de trabalhos artísticos por meio de objetos pré-existentes. Kluscinskas e Moser (2007) descrevem alguns dos procedimentos estéticos da literatura contemporânea que se inserem na premissa da reciclagem:

Quer tomemos os termos mais recentes para designar procedimentos recicladores no seu sentido mais largo - revival - remake, sampling, copy-art, ou, ainda os termos mais antigos - pastiche, paródia, plágio, reescritura recriação, reconversão -, é forçoso constatar que a produção literária contemporânea, em grande proporção está associada a esse gênero de procedimento. (KLUSCINSKAS; MOSER, 2007, p. 29) 
O procedimento realizado para a construção de "El Aleph Engordado" nos parece uma apropriação cautelosa quando analisada em relação a outros trabalhos realizados por Pablo Katchadjian (1977). O caráter monumental que a autoria de Borges evoca parece definir a ordem de apropriação que é permitida e, dessa forma, vemos que há um limite de experimentação que certos autores permitem e outros não.

Ainda assim, tal proposição se mostra um tanto paradoxal: ao mesmo tempo em que Borges é um dos precursores dos procedimentos da intertextualidade, um questionador da autoria e um apropriador (como constatamos no conto "Pierre Menard autor de Quixote"), ele é também um escritor cujo espólio está nas mãos de uma implacável guardiã de seus direitos autorais. Maria Kodama acaba figurando caricatamente como a "polícia da literatura".

Por meio da caracterização de Caso, vemos que há uma relação conturbada que se estabelece entre as noções de plágio e de apropriação. Apropriação, na chave dos estudos de literatura contemporânea, é um recurso criativo, enquanto plágio é uma categoria que se consolida no âmbito jurídico para denominar um tipo específico de fraude, na qual uma pessoa se apropria de um material produzido por outra pessoa para dizer que é seu. No Caso Pablo Katchadjian está claro que não houve a intenção de plagiar o texto de Borges.

Diversas produções literárias já foram tomadas como plágio por conta de incompreensões quanto ao teor da apropriação artística. Tomar plágio e apropriação como sinônimos resulta em análises equivocadas, pois o ato de plagiar e de apropriar não partem nem ao menos das mesmas premissas e, portanto, não podem ser lidos através das mesmas lentes. Plágio, no seu sentido mais literal, é um ato criminoso, enquanto a 
apropriação é uma forma de produção que envolve diversas questões, inclusive histórica, uma vez que retoma a estética vanguardista do século XX.

$\mathrm{Na}$ não-distinção entre plágio e apropriação reside a incompatibilidade entre autoria e propriedade jurídica, uma vez que uma das questões que permeou o Caso no decorrer do processo foi a impertinência de debates sobre procedimentos artísticos no ambiente jurídico, entendendo que advogados e juízes (normalmente) não têm domínio teórico-crítico, não sendo especialistas em procedimentos que são recorrentes e específicos dos estudos literários. Como o próprio autor Pablo Katchadjian reitera em diversas entrevistas, não houve nenhuma intenção de plagiar a Borges ou ocultar-se em seu estilo. Mas, para María Kodama, a publicação do autor foi acatada como uma afronta à grandiosa obra de Borges e, portanto, digna de uma ação judicial que perdurou por sete anos.

"El Aleph engordado" (2009) é fruto de um procedimento autoral que pode ser entendido por meio de práticas artísticas que têm como premissa o conceito da "reciclagem cultural" (KLUCINSKAS; MOSER, 2007). Mas, por meio de uma leitura pessimista, o livro pôde ser assumido como uma apropriação indevida da propriedade intelectual de Borges, já que a noção de autoria está intimamente ligada a originalidade. Na pesquisa, o conceito de originalidade foi entendido como uma noção que permite uma dissociação da produção artística que parte de um produto original. Consideramos que há originalidade em produções artística que partem de obras pré-existente (GOLDSMITH, 2014) e não são construídas do zero, rompendo com a premissa canônica do processo criativo.

Diante de tal paradigma, há duas concepções que estão colocando em questão a noção de autoria. Uma primeira concepção é a autoria compreendida como uma 
propriedade privada, um direito intelectual, um capital que precisa ser preservado, alinhando-se a uma concepção que associa os direitos autorais ao regime financeiro consolidado no século XVIII, cujo benefício primeiro foi o da editora, e não o do autor (uma lei mercadológica que serve ao capital financeiro), justificando a afirmação de Nicolas Bourriaud (2009, p. 99) que diz que o autor nada mais é que uma entidade jurídica.

Uma segunda concepção, numa perspectiva de expansão do campo (GARRAMUÑO, 2014), entende "El Aleph Engordado" (2009) como um reflexo e uma mostra do que as práticas artísticas contemporâneas permitem, sendo que essa posição otimista resulta na possibilidade de desconstrução e revisão de relatos canônicos acerca do regime autoral e das práticas de produção artística, acabando por estabelecer uma posição mais democrática dentro do campo artístico, que dialoga com os efeitos da tecnologia no século XXI.

A problemática que envolve o Caso tornou propício um estudo que objetivou compreender como as práticas artísticas contemporâneas mobilizam e reivindicam a revisão de paradigmas cristalizados no mundo da arte. Assim, surgiram questões como "quem pode reescrever a Borges?" E nós, pesquisadores, nos perguntamos "Por que Borges pode reescrever Cervantes e Katchadjian não pode reescrever Borges?". Em meio a essa tensão gerada por uma apropriação e uma acusação de plágio, surge a discussão central da pesquisa: a autoria na literatura contemporânea e, de um modo mais específico, a rasura dessa autoria. O que o gesto de Pablo Katchadjian, ao apropriar-se de Borges, nos diz a respeito dos paradigmas da autoria no âmbito do literário?

Diante desse processo de produção, apropriação, circulação e recepção não seria produtivo para o estudo a análise do texto de Pablo Katchadjian em seus aspectos 
formais ou estéticos puramente imanentes, mas sim a investigação dos processos circulação e os desdobramento da recepção que culminaram em três Objetos Derivados, visto que nos interessa uma análise que esteja em consonância com as práticas artísticas contemporâneas, evidenciando que há um circuito que orienta a circulação do literário. Estamos entendendo por processo os gestos que envolvem o contexto de produção e a recepção crítica da obra, que deixam em evidência o funcionamento específico que constituíram o Caso Pablo Katchadjian.

A natureza da criação artística dita o modo como a análise do objeto deve ser realizada, e, para esse objeto, era muito pertinente uma análise que privilegiasse os processos de circulação do literário (a configuração do Caso Pablo Katchadjian), para que se pudesse entender e evidenciar as motivações que incitaram o trabalho estético do autor.

Parte-se de uma abordagem metodológica que evidencia que os objetos artísticos presentes na cena contemporânea se colocam como um reflexo e uma possibilidade de compreender a produção e a circulação do literário no tempo presente. Diante disso, tomamos como operadores teórico-metodológicos os conceitos desenvolvidos pelo sociólogo Néstor García Canclini (2016a, 2016b) e pela pesquisadora Florencia Garramuño (2014). Esses autores apresentam criticamente possibilidades de leituras que consideram e legitimam as relações que estão em jogo no campo artístico expandido:

Tanto nas ciências como nas artes, o conceito de campo acabou com a noção romântica e individualista do gênio que descobre conhecimentos imprevistos ou cria obras excepcionais que surgem do nada. Sem cair, tampouco, no determinismo macrossocial que queria explicar os romances ou as pinturas pela posição de classe e pelo modo de produção. Ao restringir-se à estrutura interna de cada campo e às regras específicas para produzir arte ou literatura, a pesquisa sociológica deu instrumento para ler as obras não como surgida do nada, mas no contexto das relações entre criadores, intermediários e público. (CANCLINI, 2016b, p. 86, grifo nosso) 
Quando falamos de "processos" estamos justamente pensando na proposição de Canclini (2016b) de que as obras literárias surgem no contexto das relações entre criadores, intermediários e públicos. A constatação de Canclini dá subsídio para que se tenha como corpus o livro "El Aleph Engordado" (2009), relacionando a sua recepção aos seus processos de circulação e legitimação.

Sabemos que o Caso deu origem a outros produtos culturais, aqui entendido como Objetos derivados, que terminam constituindo e alterando o modo como se lê "El Aleph Engordado" (2009). São eles: i) uma plataforma digital intitulada YoBorges - na qual todos os versos de todos os poemas de Borges foram emulados, possibilitando que qualquer pessoa que tenha um computador conectado à rede possa compor um poema a partir deles; ii) uma página no Facebook intitulada "Apoyo a Pablo Katchadjian" na qual foram veiculadas entrevistas e notícias com o autor, com a viúva de Borges e com críticos como Cesar Aira, bem como trabalhos de Borges que confirmam que o autor estaria em consonância com as práticas de Katchadjian. Com as sucessões de acusação e contraacusação surge um jogo; iii) Reality Avoider, que se apresenta como um gesto performático por colocar a face de Maria Kodama em um bloco que deve desviar-se das várias palavras "realidade" que vêm ao seu encontro, corroborando com a ideia de que Kodama estaria alienada ante os atuais procedimentos de criação literária.

Esses objetos culturais derivados são explicitamente produtos do contexto digital, uma constatação que reivindica pensar, ainda que brevemente, o conceito de Cibercultura (Cf. LEVY, 1999) como um conjunto de práticas que alteram as esferas culturais e sociais e não são somente resultados de avanços técnicos. Nesse sentido, a noção de rede de compartilhamento, a questão da interação entre usuários e autores - 
potencializada no marco da Web 2.0 - nos dá argumento para constatar que a categoria autoral é interpelada pelas práticas de seu tempo, e que nosso século marca mudanças significativas no campo da arte devido à presença da digitalidade. Como nos mostram Kluscinskas e Moser (2007) ao dizer que a "teoria das mídias mostra como as novas tecnologias modificam nossas experiências do mundo, porque elas mudam, na realidade, as próprias condições da experiência estética" (KLUCINSKAS; MOSER, 2007, p.28).

É nesse cenário que está caracterizada a Web 2.0 - buscando, além do avanço da técnica a interação e a troca entre usuários, uma participação ampliada, que reflete e altera a produção literária e seu regime de funcionamento. A tecnologia entra na esfera da literatura conferindo mudanças em seus processos.

\begin{abstract}
A etapa mais recente está representada pela web 2.0, onde circulam tantas "criações" de artistas e de usuários - o que os criadores iniciam e outros modificam - que as fronteiras entre arte e não arte se "desdefinem". Todos os propósitos da arte de diferentes épocas subordinam-se à tendência de ampliar a participação. Diz-se que uma rede é melhor quando mais usuários incluir, quando incrementa sem cessar vídeos, fotografias e blog. (CANCLINI, 2016b, p. 51)
\end{abstract}

A circulação do livro "El Aleph Engordado" (2009) está marcada pelos dizeres que o constituem, sendo que os objetos acima mencionados, entendidos como Objetos Derivados, dão base para um contexto que altera a leitura do texto justamente por serem produzidos por uma rede de participação. Estamos entendendo como Objetos Derivados, portanto, aqueles objetos produzidos no contexto digital e, que foram de certo modo apropriados pelo Caso Pablo Katchadjian. Podemos pensar em Objetos derivados como produtos culturais que surgem e são efeito de uma determinada produção literária, orientando e alterando seu funcionamento e seus processos de circulação. 


\section{Considerações finais}

"El Aleph Engordado" (2009) foi lido de acordo com os questionamentos propiciados por uma ação judicial e por três Objetos Derivados criados em plataformas conectadas à internet, que por fim reprogramaram o modo como o livro figura na cena contemporânea. Buscamos entender o modo como Katchadjian circula e se legitima, tendo como premissa que o autor assume e interpreta as características de um autor performático (Cf. AZEVEDO, 2006).

Paralelamente, questionamos o lugar monumental atribuído a Jorge Luís Borges e as consequências desse imaginário para a manutenção de sua autoria. Diante de todas essas questões, operacionalizamos as noções de campo expandido, frutos estranhos, arte inespecífica e práticas da impertinência, conceitos que orientam a leitura de objetos artísticos para além das formalizações clássicas da arte (música, pintura, literatura) individualizada. É uma possibilidade de abordagem que dá abertura tanto para produtos artísticos em suas variadas formas quanto para instrumentos analíticos que comtemplem essa hibridização.

Há espaço para uma hibridização de categorias artísticas, não privilegiando uma arte em detrimento de outra, destacando que é na expansão do campo artístico que está o valor dessas produções:

A expansividade dos meios e suportes artísticos se reconhece em práticas contemporâneas que, com operações, materiais e suportes muito diferentes entre si, foram desmantelando, detida e minuciosamente, todo tipo de ideia do próprio, tanto no sentido do identifico a si mesmo como no sentido de limpo ou puro, mas também no sentido do próprio como aquela característica que diferencia, porque seria própria, uma espécie da outra. (GARRAMUÑO, 2014, p. 95) 
Nessa ideia da expansividade concebida por Florencia Garramuño (2014) está a premissa do rompimento de barreiras entre artes e não arte, também uma incorporação de práticas entre as artes, como o caso do autor-curador (AZEVEDO, 2017), que mostra uma prática própria da esfera museológica entrando na cena literária.

Há, ainda, uma discussão em relação ao rompimento das barreiras entre produtos artísticos e objetos manufaturados, trazendo para o mundo da arte o que não é considerado próprio e levando arte a lugares não-especificamente artísticos. Tal atitude mostra que não há espaços adequados para a inserção do literário - presente em instalações, em feiras e em centros comerciais, por exemplo. São práticas que mostram uma diluição da especificidade e da autonomia da arte (Cf. CANCLINI, 2012a). Essa mudança de paradigma, que está na expansão do campo literário, exige que busquemos formas de análise e leitura interdisciplinares, pois não é viável olhar para o novo com os instrumentos que guiaram produções anteriores e mais que isso baseada em outros preceitos de produção.

O conceito de autor-curador, discutido por Luciene Azevedo, permite pensar a produção literária contemporânea pelo viés da curadoria, sendo o curador aquele que, a partir de seu olhar, relaciona e reorganiza os objetos. Há uma perspectiva que constitui a análise de objetos e obras literárias, mas que transbordam o reconhecido como específico do estudo crítico da literatura.

Faz-se necessário o estudo dos processos que deram, ou darão, ao literário um lugar de legitimidade, perspectiva essa que parte de uma concepção não essencialista de literatura, uma vez que, para questionar os mecanismos pelos quais um autor foi consolidado, é incontornável considerar que a literatura é uma instituição previamente estabelecida e com base em preceitos específicos, dentre eles estão a cultura impressa, o 
suporte impresso, a autoria, a originalidade e as estratégias de legitimação amparadas pelo mercado livreiro. De acordo com Regina Dalgastagné (2017), a perspectiva não essencialista de leitura e análise do literário abre possibilidade para compreendê-lo de modo que se enfatize as disputas que estão em jogo no processo de legitimação e, ainda, para que se entenda os mecanismos que tornam possível a constituição de um texto enquanto literários. Essa perspectiva desmistificada abre caminho para o reconhecimento de novas literaturas.

\footnotetext{
Essa maneira de compreender o funcionamento do fenômeno literário abre amplas possibilidades para conhecer obras, autores, tendências que ficaram fora de uma determinada tradição ou que, em uma época concreta, não ocuparam posições destacadas dentro do sistema (Villarino Pardo, 2000, p. 1023). Considerar sua existência contribui para entender melhor a posição de prestígio que ocupam outros elementos da rede literária, assim como as relações (ou a mínima presença delas) e as dinâmicas de que participam como integrantes do mesmo campo (Bourdieu, 1996). Estão em jogo os processos de valorização que se aplicam dentro de um sistema a determinados produtos literários, destacando que não se trata de uma caraterística inerente a eles, mas do resultado de uma série de disputas. (PARDO; DALCASTAGNÈ, 2017, p. 14)
}

Na problematização do fenômeno literário por Florencia Garramuño (2014) sobre a expansividade do campo e os gestos tidos como inespecíficos - reside a noção de comunidade expandida. As comunidades são expandidas no sentido em que, nessas distorções do já consolidado, surge a possibilidade do comum, mas comum pela diferença, é na diversidade que os relatos se somam. Nesse contexto, a diferença é o rompimento das barreiras literárias, tanto no ato criativo quanto na investigação. Para Florencia Garramuño "essa aposta no inespecífico seria um modo de elaborar uma linguagem do comum que propiciasse modos diversos do não pertencimento" (2014, p. 16). 
Compreende-se, por fim, "El Aleph Engordado" (2009) colocando em perspectiva a ressignificação do modo como os objetos artísticos são lidos contemporaneamente, entendendo que "o objeto literário é, mais do que as obras ou o ato inapreensível da criação, o processo sociocultural de sua elaboração, seu tráfico e as modulações em que se altera seu sentido" (CANCLINI, 2016b, p. 96).

\section{Referências}

AIRA, Cesar. El tempo y el lugar de la Literatura. Otra Parte, Argentina, n. 19. Disponível em: http://revistaotraparte.com/no-19-verano-2009-2010/el-tiempo-y-el-lugar-de-laliteratura. Acesso em: 05 jun. 2020.

ARGENTINA. Ley $N^{\circ}$ 11.723, Régimen Legal de la Propiedad Intelectual. Disponível em: https://www.wipo.int/edocs/lexdocs/laws/es/ar/ar012es.pdf Acesso em: 14 jun. 2020.

AZEVEDO, Luciene. Estratégias para enfrentar o presente: A performance, o segredo e a memória. 2004. 207 f. Dissertação (Doutorado) - Universidade estadual do Rio de Janeiro - UERJ, Rio de Janeiro, 2004.

Autoria e Performance. Revista de Letras, São Paulo, 47 (2): 133 -158 jul/dez 2007.

Romances não criativos. Revista Estudos de Literatura Brasileira Contemporânea. n. 50, 2017. Disponível em:

http://periodicos.unb.br/index.php/estudos/article/view/24138. Acesso em: 05 jun. 2020.

Daniel Galera: profissão escritor. Revista Inventário. Disponível em: http://www.inventario.ufba.br/12/ENSAIO\%20LUCIENE\%20AZEVEDO.pdf. Acesso em: 05 jun. 2020.

Pirataria literária tem valor? Revista abehache, 2011. Disponível em:

http://revistaabehache.com.br/index.php/abehache/article/view/35/34. Pdf. Acesso em: 05 jun. 2020.

AZEVEDO, Luciene; CAPAVERDE, Tatiana da Silva. Escrita não criativa e autoria. e-gálaxia, 2018.

BARTHES, Roland. A morte do autor. In: . O rumor da língua. 2 ed. Trad. Mario Laranjeira. São Paulo: Martins Fontes, 2004. P. 57-64 
BORGES, Luis Jorge. Pierre Menard autor de Quixote. In: Ficções. Trad. Carlos Nejar. Porto Alegre: Abril, 1972.

BOURRIAUD, NICOLAS. Pós-produção como a arte da reforma: o mundo contemporâneo. Trad. Denise Bottman. São Paulo: Martins Fontes, 2009.

CANCLINI, Néstor García. A sociedade sem Relato: Antropologia e Estética da Iminência. Trad. Maria Paula Gurgel Ribeiro. São Paulo: Edusp, 2016a.

O mundo inteiro como lugar estranho. Trad. Larissa Fostinone Locoselli. São Paulo: Edusp, 2016b.

CHARTIER, Roger. O que é um autor? Revisão de uma genealogia. Trad. Luzmara Cursino; Carlos Eduardo de Oliveira Bezerra. São Carlos: EdUFSCar, 2012.

COMPAGNON, Antoine. O trabalho da citação. Trad. Cleonice P. B. Mourão. Belo Horizonte: Ed. UFMG, 1996.

FOUCAULT, Michel. Ditos e escritos III. In: . Estética: literatura e pintura, música e cinema. Trad. Inês Autran Dourado Barbosa. Rio de Janeiro: Forense Universitária, 2001.

GARRAMUÑO, Florencia. Frutos estranhos: sobre a inespecificidade na estética contemporânea. Trad. Carlos Nouguê. Rio de Janeiro: Rocco, 2014.

GOLDSMITH, Kenneth; BEIGUELMAN, Giselle (Trad.). Copiar é preciso, inventar não é preciso. Revista seLecT, 2011. p. 37-43.

KLUSCINSKAS, Jean; MOSER, Walter. "A estética à prova da reciclagem cultural". Trad. Cleonice Mourão. SCRIPTA, Belo Horizonte, v. 11, n. 20, p.17-42, 1ำ sem. 2007.

KATCHADJIAN, Pablo. El Aleph Engordado. Buenos Aires: Imprenta Poesia Argentina, 2009.

LEVY, Pierre. Cibercultura. Trad. Carlos Irineu da Costa. São Paulo: Editora 34, 1999.

PARDO, M; DALGASTGNÈ, R. Lugares do Literário. Revista Estudo de literatura brasileira contemporânea, n.50, p. 13-17, Jun/abril. 2017

YOBORGES. Yoborges.ar. Disponível em: https://www.yoborges.com.ar. Acesso em: 26/05/2019. 
${ }^{1}$ Nasceu em 10 de março de 1937. É escritora, tradutora e professora de literatura Argentina, foi casada com Jorge Luis Borges e é herdeira e detentora de seus direitos autorais.

2 "O Aleph engordado. É o conto de Borges expandido, expandido "por dentro", acrescentando palavras, frases, episódios, "catalisando" por meio de aposições sem alterar o enredo ou adicionar personagens, de modo a tornar a história de dez páginas uma novela, curta mas novela, ou melhor, não entrar na discussão de gêneros, 'um livro'." Tradução nossa.

${ }^{3}$ A autora fala do caso de apropriação de Di Nucci, que publicou o livro Bolivia construcciones. Artigo sobre o caso: https://larrlasa.org/articles/10.25222/larr.49/ acesso em 20/11/2018

4 “Ninguém tem o direito de publicar, sem a permissão dos autores ou de seus titulares, uma produção científica, literária, artística ou musical que tenha sido anotada ou copiada durante sua leitura, apresentação ou exibição pública ou privada." Tradução nossa. 